\title{
Disain Kebijakan Pengelolaan Perikanan Budidaya Untuk Menunjang Ekosistem Danau Limboto Lestari
}

\author{
Hasim \\ Jurusan Teknologi Perikanan, Fakultas IImu-IImu Pertanian Universitas negeri Gorontalo
}

\begin{abstract}
Abstrak
Perikanan budidaya sistem Karamba Jaring Apung (KJA) berkembang pesat di Danau Limboto. Perkembangan tersebut tidak semata memberikan dampak ekonomi tetapi juga berdampak negative terhadap lingkungan perairan. Oleh karena itu telah dilakukan penelitian dengan fokus tujuan (1) mengkaji kelayakan kondisi perairan Danau Limboto untuk pengembangan KJA; (2) mendesain kebijakan pengelolaan budidaya sistem KJA yang berkelanjutan. Metode penelitian menggunakan survey. Data fisik diukur secara langsung di lapangan, sedangkan responden pakar melalui wawancara terstruktur terhadap 7 responden pakar. Analisis yang digunakan yaitu winexsys, ISM dan AHP. Hasil penelitian menunjukkan bahwa tidak semua lokasi danau sesuai untuk pengembangan perikanan budidaya. Faktor kebijakan, pemerintah, daya dukung dan pengelolaan berbasis masyarakat prioritas untuk diperhatikan. Sedangkan elemen kunci untuk pengembangan kebijakan ialah sinergi, egosektoral, dan pengendalian sedimen.
\end{abstract}

Kata kunci: Status keberlanjutan dan disain kebijakan

\section{PENDAHULUAN}

Danau Limboto merupakan danau yang memiliki peran sangat penting di Gorontalo. Karena masyarakat pesisir danau memiliki ketergantungan ekonomi yang tinggi. Bedasarkan studi literatur terdapat 329 RTP dengan system KJA dan 1454 RTP nelayan, sedangkan nelayan bibilo mencapai 785 RTP (Badan Riset Kelautan dan Perikanan, 2007). Dengan demikian seluruh RTP di danau Limboto ialah 2569. Bila masing-masing RTP terdapat dua kepala rumah tangga, maka ada 5138 rumah tangga. Bila asumsinya satu rumah tangga terdapat 4 anggotanya, maka penduduk yang memiliki ketergantungan ekonomi terhadap danau ialah 20.552 jiwa.

Perairan danau Limboto mengalami eutropikasi yang tinggi. Hal tersebut ditunjukkan oleh tanaman air, hampir 50 persen dari luas permukaan danau, (Sarnita, 1993). Menurut Boyd (1998) bahwa populasi tanaman air yang mencapai 10-20 persen dari luas permukaan perairan akan menyulitkan pengelolaan perikanan. Atas dasar kondisi tersebut danau Limboto oleh KLH masuk dalam 10 danau yang tergolong kritis.

Sejak tahun 1988 telah dilakukan uji coba perikanan budidaya dengan jaring apung di danau Limboto. Kegiatan perikanan budidaya ini mengalami perkembangan setiap tahunnya. Hal tersebut ditunjukkan oleh jumlah Karamba Jaring Apung (KJA) yang mengelami kenaikan. Pada

tahun 1993 jumlah KJA 500 unit dan berkembang menjadi 1.962 unit pada tahun 2007. Sedangkan jumlah pembudidaya ikan ialah 329 RTP (Badan Riset Kelautan dan Perikanan. 2007). Umumnya jenis ikan yang dipelihara ialah ikan nila Oreochromis nilaticus, ikan mujair Oreochromis musambica dan ikan mas Cyrprinus carpio.

Beberapa hasil penelitian melaporkan bahwa perikanan budidaya intensif dan pengkayaan nutrien berdampak potensial pada perubahan kualitas air (Johansson et al., 1997; Boyd, 1998). Mc Donad et al., (1996) menyatakan bahwa 30\% dari jumlah pakan yang diberikan tertinggal sebagai pakan yang tidak dikonsumsi dan $25-30 \%$ dari pakan yang dikonsumsi akan diekskresikan. Ini berarti jumlah yang cukup besar masuk ke badan air. Selanjutnya Haven et. al. (2001) dan Johansson et.al. (1998) menyatakan bahwa perikanan budidaya di danau memiliki limbah organic tinggi dan berperan dalam eutrofikasi.

Gubernur Gorontalo (Era Fadel Muhammad) dalam beberapa kesempatan menyampaikan pemikirannya untuk menjadikan danau Limboto sebagai kawasan Industri Perikanan Budidaya. Pertimbangannya ialah market komoditas perikanan budidaya sangat prospek di luar negeri. Pandangan rent seeking untuk mengkapitalisasi danau melalui perikanan budidaya tersebut penting mendapat perhatian serius. Karena dalam kondisi danau Limboto yang sudah kritis, menambah beban produktivitas perikanan budidaya 
memberi ancaman ekologis. Oleh sebab itu perlu dilakukan penelitian untuk mengkaji disain kebijakan pengelolaan danau yang menunjang perikanan budidaya lestari. Hasil penelitian ini

\section{METODE PENELITIAN}

Pelaksanaan penelitian bulan November 2011 - Maret 2012. Penelitian ini dilakukan dengan kombinasi antara metode survey dengan library research. Metode survey yaitu pengumpulan data berdasarkan observasi dan pengukuran lapangan berbasis sampel. Lokasi stasiun pengukuran kualitas air ditentukan secara purposive dari mulai bagian tengah danau hingga ke arah darat yang Analisis penentuan kesesuaian danau menggunakan system pakar berbasis winexsys (Marimin, 2007) . Berdasarkan telaah literature dan fakta lapangan dibangun basis pengetahuan sebagai qualifier sebagai berikut.

\section{Kedalaman Danau:}

1) Kedalaman 3-4 meter Tidak Sesuai

2) Kedalaman 5-6 meter Kurang Sesuai

3) Kedalaman $>7-8$ meter Sesuai

4) Kedalaman $>8$ meter Sangat Sesuai;

\section{Kandungan Oksigen Terlarut:}

1) Kandungan Oksigen Terlarut 2 - $3.5 \mathrm{mg} / \mathrm{tt}$ Tidak Sesuai

2) Kandugan Oksigen Terlarut $3.5-<4.6$ $\mathrm{mg} / \mathrm{lt} \quad$ Kurang Sesuai

3) Kandungan Oksigen Terlarut $4.5-<$ $6 \mathrm{mg} / \mathrm{lt} \quad$ Sesaui

4) Kandungan Oksigen Terlarut $6 \mathrm{mg} / \mathrm{tt}$ Sangat Sesuai

\section{Kandungan Amonik:}

1) Kandungan Amoniak $>0.1$ Tidak Sesua

2) Kandungan Amoniak $0.1->0.01 \mathrm{mg} / \mathrm{tt}$ Kurang Sesuai

3) Kandungan Amoniak 0,01 - > $0.001 \mathrm{mg} / \mathrm{tt}$ Sesuai

\section{HASIL DAN PEMBAHASAN}

Kesesuaian perairan untuk kegiatan pengembangan perikanan budidaya di Danau Limboto dilakukan dengan mengukur beberapa parameter utama seperti kedalaman, oksigen diharapkan dapat menjadi informasi penting termasuk bagi pemerintah dalam merumuskan kebijakan pengelolaan Danau Limboto agar bisa dipulihkan.

terdapat kegiatan budidaya KJA atau jaring tancap. Jumlah stasiun 4 meliputi di kedalaman 5 meter, 3 meter, 2 meter dan 1,5 meter. Data dianalisis secara exsitu dan insitu. Sedangkan data pakar dilakukan secara wawancara terhadap tujuh responden pakar yang memiliki kompotensi di bidang terkait obyek penelitian.

4) Kandungan Amoniak $0.001 \mathrm{mg} / \mathrm{lt}$ Sangat Sesuai

\section{Kandungan TSS:}

1) Kandungan TSS $\geq 500$ Tidak Sesuai

2) Kandungan TSS $300-100 \mathrm{mg} / \mathrm{l}$ Kurang Sesuai

3) Kandugan TSS 100-300 mg/l

4) Kandungan Sesuai

\section{Sangat Sesuai}

TSS $<1000 \mathrm{mg} / \mathrm{l}$

Alternatif keputusan yang digunakan dalam menarik kesimpulan kelas kesesuaian danau untuk pemanfaatan perikanan budidaya ialah menggunakan sistem pakar berbasis winexsys berupa Choice atau output dari sistem pakar, yaitu:

1. Sangat Sesuai

2. Cukup Sedang

3. Tidak Sesuai

Penentuan alternatif keputusan didasarkan atas Nilai Komulatif kesesuaian yaitu:

1. $13 \geq$ Sangat Sesuai

2. $8<\mathrm{NK} \leq 12$ Cukup Sesuai

3. NK $<8$ Tidak Sesuai

Struktur hirarki yang menunjukkan hubungan antara kriteria dan level masing-masing dengan tingkat keputusan disajikan pada gambar di bawah.

terlarut, amoniak dan TSS. Pengukuran kualitas air di lakukan pada empat stasion pengamatan. Hasilnya disajikan pada tabel di bawah ini. 
Tabel 1. Parameter Kualitas air dan kedalaman perairan

\begin{tabular}{l|l|l|l|l}
\hline Paramter & Stasiun I & Stasiun II & $\begin{array}{l}\text { Stasiun } \\
\text { III }\end{array}$ & Stasiun IV \\
\hline Kedalaman & 5 & 3 & 2 & 1.5 \\
Oksigen Terlarut (mg/lt) & 6 & 4 & 4 & 4 \\
Amoniak (mg/t) & 0,255 & 0,57 & 0,9 & 0,38 \\
TSS $(\mathrm{mg})$ & 100 & 100 & 350 & 300 \\
Keterangan & Sesuai & $\begin{array}{l}\text { Sesuai } \\
\text { marginal }\end{array}$ & Tidak & Sesuai \\
\hline
\end{tabular}

Berdasarkan data tersebut kemudian diinput kedalam program winexsys yang telah dibangun basis pengetahuan dan mesin inferensi tentang kesesuain lahan untuk perikanan budidaya. Tabel 1 di atas menunjukkan bahwa kedalaman menjadi faktor utama dalam kesesuaian kegiatan perikanan budidaya di Danau Limboto. Idialnya kedalaman kolom air untuk kegiatan budidaya minimal 6 meter, agar jarak antara jaring KJA dengan dasar danau tidak terlalu dekat. Karena dekatnya jarring bagian bawah ke dasar danau memiliki resiko keracunan gas anorganik dari dasar sangat tinggi. Hal tersebut sejalan dengan informasi pembudidaya bahwa sering terjadi kematian ikan secara massal di Danau Limboto. Kematian massal mengindikasi terdapatnya senyawa kimia yang bersifat racun yang disebabkan oleh naiknya gasgas tersebut dari dasar ke bagian lapisan atas.

Berdasarkan hasil analisis kesesuaian yang disajikan pada tabel di atas selanjutnya dilakukan analisis arah pengembangan kebijakan pengelolaan perikanan budidaya yang mendukung Danau Limboto Lestari menggunakan AHP. Hasilnya disajikan dalam bentuk bagan pada gambar 1 di bawah ini.

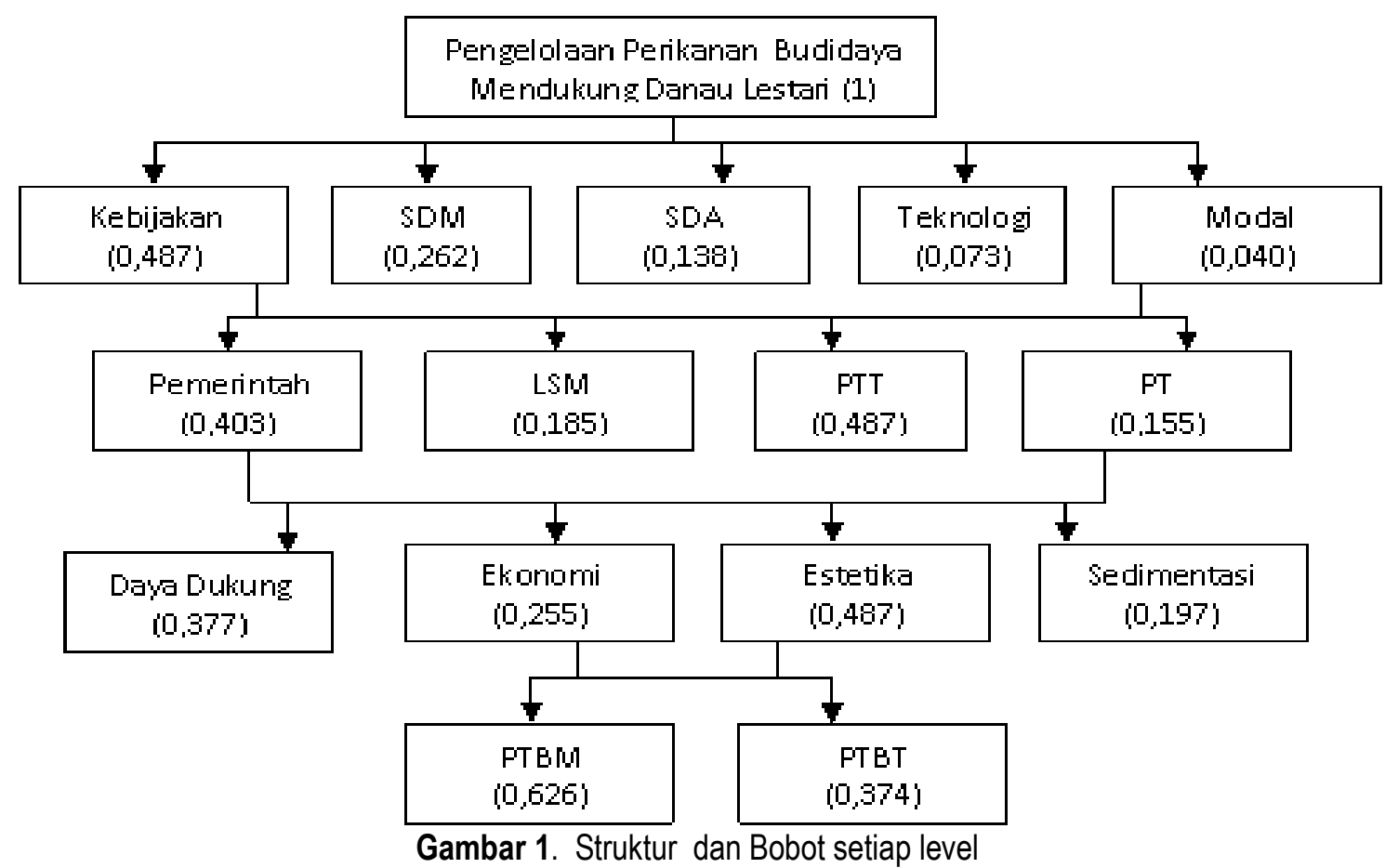

Bagan di atas terdiri atas lima level yaitu level faktor, level aktor, level tujuan dan level alternative. Berdasarkan analisis AHP menunjukkan bahwa pada level factor, factor yang memiliki skor tertinggi dibanding factor lainnya ialah kebijakan $(48,7 \%)$. Artinya factor kebijakan memiliki pengaruh paling besar terhadap pencapain focus dibandingkan faktor lainnya. Pada level aktor, menunjukkan aktor yang paling tinggi skornya ialah pemerintah (40,3\%). Artinya pemerintah sangat berpengaruh dalam melahirkan kebijakan pengelolan perikanan budidaya yang mendukung kelestarian Danau Limboto. Oleh karena itu pemerintah harus memiliki inisiasi dan komitmen 
yang tinggi guna merealisasikan pengelolaan perikanan budidaya yang mendukung kelestarian Danau Limboto. Misalnya mengoptimalkan pelaksanaan PERDA Pengelolaan Danau Limboto. Memfasilitasi terbentuknya kelembagaan Danau Limboto yang mewadahi berbagai pemangku amanah. Memfasilitasi penyusunan Rencana Tata Ruang Kawasan Danau beserta zonasinya. Pada level tujuan, menunjukkan bahwa tujuan keberlanjutan daya dukung danau ialah yang tertinggi $37,7 \%$. Artinya daya dukung danau menjadi faktor kunci bagi pencapain kebijakan pengelolaan danau. Sedangkan pada level alternative, menunjukkan bahwa pengelolaan terpadu berbasis masyarakat menjadi prioritas untuk disain kebijakan pengelalaan perikanan budidaya di danau. Seperti yang Sarch (2001) nyatakan bahwa berbagai pihak memiliki kepentingan untuk mengakses sumberdaya di danau, sehingga dibutuhkan kebijakan seperti regulasi untuk mengaturnya dengan mempertimbangkan kondisi karakteristik danau dan aspek sosial-budaya di dalamnya.
Berdasarkan analisis system pakar berbasis ISM menunjukkan bahwa pada elemen tujuan, subelemen 1 (sinergisitas antara sector) dan subelemen 2 (sedimentasi sekecil mungkin) berada pada kuadaran Independen. Artinya subelemen ini merupakan elemen kunci. Elemen kunci adalah memiliki kekuatan peggerak terbesar dalam pencapaian tujuan kebijakan pengelolaan perikanan budidaya di danau Limboto. Sedangkan subelemen 5,6,dan 7 berada pada kuadran linkage, artinya subelemen tersebut akan memberikan dampak, tetapi sebaliknya subelemen tersebut sensitive terhadap elemen lainnya. Subelemen 3 dan 4 sangat dipengaruh subelemen lainnya. Hal tersebut sesuai dengan Kodratyev et all., (2002) bahwa sedimentasi danau banyak dipengrauh oleh aktivitas pembangunan ekonomi yang ada di kawasannya. Dengan demikian sinergisitas antara aktivitas kawasan akan mengendalikan sedimentasi yang terjadi di danau.

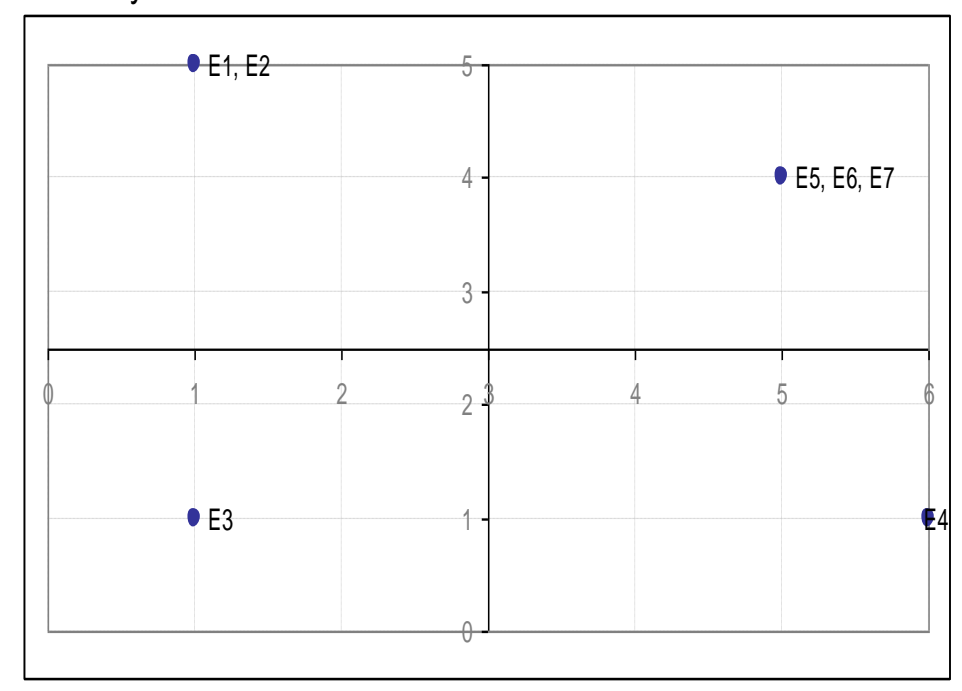

Gambar 2. Matriks Driver Power Dependence untuk Elemen Tujuan

Elemen kebutuhan menunjukkan bahwa subelemen 3 (pemberdayaan masyarakat) dan 4 (partisipasi masyarakat) berada dikuadran independen merupakan elemen kunci. Artinya subelemen tersebut memiliki penggerak terbesar dalam pemenuhan subelemen lainnya pada elemen kebutuhan stakeholder. Sedangkan elemen 5 (kualitas peraiaran) memiliki pengggerak yang besar jika didukung oleh subelemen pada sector kuadran independen. Subelemen 1,2, 6 dan 7 sangat tergantung terhadap subelemen lainnya. 


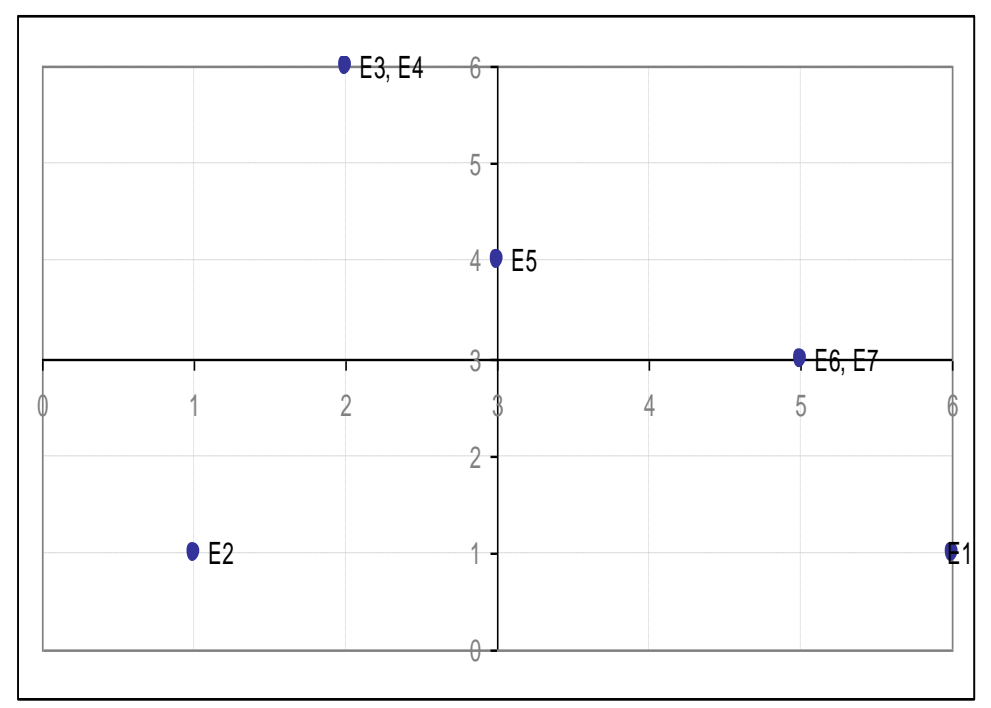

Gambar 3. Matriks Driver Power Dependence untuk Elemen Kebutuhan

Elemen kendala menunjukkan bahwa subelemen 1 (egosektoral) dan subelemen 7 (berada di dua wilayah kota/kabupaten) berada disektor kuadran dependen, jadi merupakan elemen kunci. Artinya subelemen tersebut memiliki daya penggerak tinggi terhadap subelemen kendala lainnya. Sehingga bila subelemen ini teratasi maka akan berpengaruh terhadap pemecahan subelemen kendala lainnya. Sebaliknya jika subelemen tersebut tetap menjadi kendala, maka subelemen lainnya akan terpengaruh menjadi subelemen kendala. Sedangkan subelemen 4 (penegakan hukum) dan subelemen 5 (okupasi) berada pada sector linkage. Artinya memiliki daya gerak besar jika diungkit oleh subelemen independen.

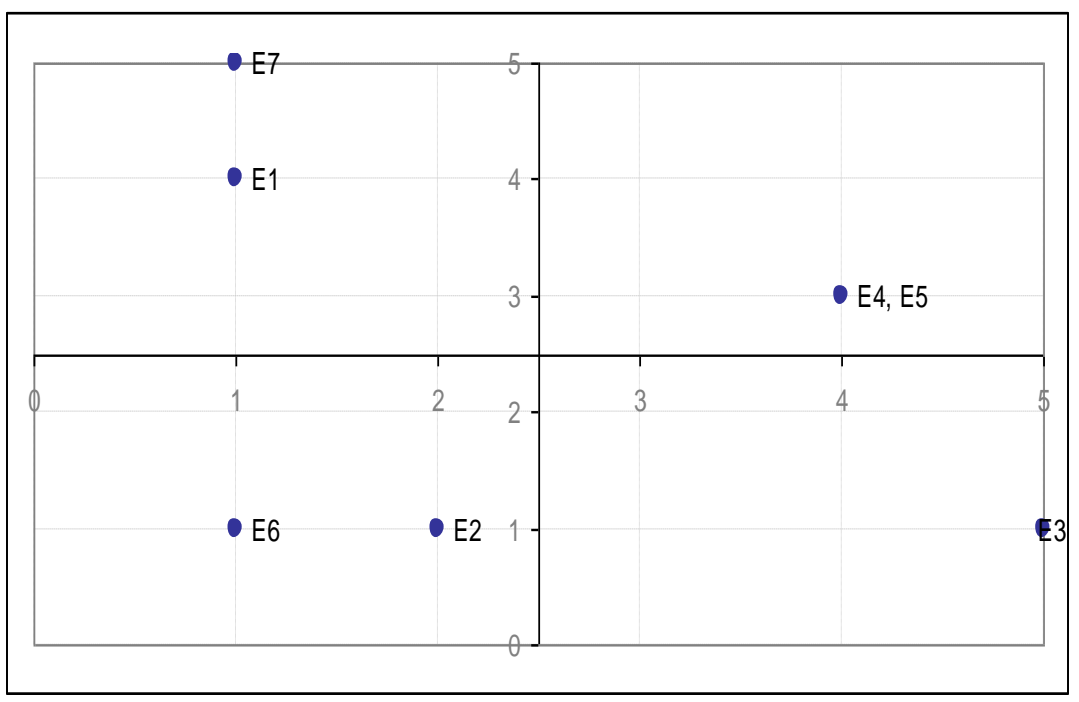

Gambar 4. Matriks Driver Power Dependence untuk Elemen Kendala

Berdasarkan hasil analisis ISM tersebut di atas memberikan arahan tafsir bahwa sinergisitas dan pengurangan sedimen secara signifikan menjadi elemen kunci pada elemen tujuan pengelolaan perikanan budidaya yang menunjuang kelestarian danau. Artinya pemerintah dan pengampuh kepentingan harus memiliki komitmen yang sama dalam mewujudkan sinergisitas. Untuk elemen kebutuhan yang menjadi elemen kunci ialah partisipasi dan pemberdayaan. Artinya partisipasi dan pemberdayaan masyarakat faktor penting jika kegiatan perikanan budidaya diorientasikan untuk 
mendukung kelestarian danau. Secara obyektif jamak disadari bahwa model pembangunan yang top down telah mematikan kreativitas dan kecerdasan lokal. Implikasinya masyarakat hanya menjadi obyek pembangunan,sebaliknya tidak menjadi subyek pembangunan. Padahal pemberdayaan dan partisipasi dari masyarakat akan melahirkan sikap dan perilaku bertanggungjawab terhadap alam dan lingkungannya. Sedangkan elemen kunci pada elemen kendala ialah egosektoral dan berada diantara dua kabupaten/kota. Kondisi egosektoral lahir dari pendekatan pembangunan yang sektoral, sehingga antara satu sektor dengan sektor lainnya tumpah tindih. Pendekatan sektoral dalam pembangunan impak dari orintasi pembangunan yang mengedepankan ekonomi sebaliknya mengabaikan ekologi dan sosial. Sisi lain, wilayah Danau Limboto yang berada di dua wilayah memberikan dampak positif jika mampu membangun sinergi antara dua daerah tersebut. Sebaliknya akan memberikan dampak negatif jika mengedepankan perbedaan kepentingan. Hal tersebut sejalan dengan pendapat Catro and McGrath (2003) bahwa perlu payung regulasi sehingga monitoring terhadap kegiatan yang terjadi di danau dan penegakan hukum terkait aktivitas dapat berlangsung secara efektif.

\section{KESIMPULAN}

1. Stasiun yang memiliki status cukup sesuai untuk kegiatan perikanan budidaya ialah stasiun 1 dan 2. Sedangkan stasiun 3 dan 4 tergolong tidak sesuai;

2. Bobot tertinggi dalam hirarki struktur kebijakan adalah; untuk level factor ialah kebijakan, level actor pemerintah, level tujuan daya dukung dan level alternative adalah pengelolaan terpadu berbasis masyarakat;

3. Elemen kunci pada subelemen tujuan yaitu; subelemen 1 (sinergisitas antara sector) dan subelemen 2 (sedimentasi sekecil mungkin) berada pada kuadaran Independen. Elemen kunci pada elemen kebutuhan ialah subelemen 3 (pemberdayaan masyarakat) dan 4 (partisipasi masyarakat). Sedangkan elemen kunci pada elemen kendala yaitu subelemen 1 (egosektoral) dan subelemen 7 (berada di dua wilayah kota/kabupaten).

\section{Daftar Pustaka}

Badan Riset Kelautan dan Perikanan. 2007. Monografi Sumberdaya Perikanan Danau Limboto. Departemen Kelautan dan Perikanan.

Byod,C.E. 1998. Water Quality in Warmeter Fish Ponds. Auburn University Agricultural Experiment Station, Alabama.

De Castro F and McGrath, D.G.2003. Moving toward Sustainability in the Local Management of floodplain Lake Fishery in the Brazilian Amazon. Human Organization; 6, .2.

McDonald ME, Tikkanen CA, Axler RP, Larsen CP, Host GS. 1996. Fish Simulation Culture Model: a bioenergetic based model for aquaculture waste load application. Aquaculture Engineering 15:243-259.

Johansson, T., Håkanson, L., Borum, K. and Persson, J. 1998. Direct Flows of Phophorous and Suspended Metter Form a Fish Farm to Wild Fish in Lake Southren Bollarean, Sweden. Aquacultue Engineering, 17 (1998) 111-137.

Havens KE, Fukushima $T$, Xie $P$, Iwakuma $T$, James RT, Takamura N, Hanzato T, Yamamoto. 2001.Nutrien Dinamyc and the Euthropication of Shallow Lake Kasumiguara (Japan), Dongu (PR China) and Okeechobe (USA). Environmental Pollution Journal, 111: 263-272.

Kondratyev S. Gronskaya T, Ignatieva N, Blinoval I, Telesh I, Yefremova L. 2002. Assessment of present state of water resources of Lake Ladoga and its drainage basin using Sustainable Development indicators. Ecological Indicators 2 (2002) 79-92.

Lenters, J.D. 2005. Effects of climate variability on lake evaporation: Results from a long-term energy budget study of Sparkling Lake,northern Wisconsin (USA). Journal of Hydrology 308 (2005) 168-195. 
Marimin, 2007. Teori dan Aplikasi. Sistem Pakar dalam Teknologi Manajerial. IPB

Sarita A, Purnomo K, Umar C, Setyaningsih L. 1994. Laporan Hasil Penelitian Perikanan Danau Limboto. Jatiluhur: Sub Balai Penelitian Perikanan Air Tawar, Departemen Pertanian.
Press, Bogor.

Sarch.MT.2001. Fishing and Farming at Lake Chad: Institution for Access to Natural Resources. Journal of Natural Management, 62:185-199. 